\title{
Nuevos agentes en la gestión ambiental: El caso de las organizaciones de la sociedad civil en Ensenada
}

\section{New actors in environmental management: The case of the civil society in Ensenada}

Nain Martínez* y Refugio Chávez Ramírez**

Resumen

El medio ambiente es un espacio complejo en el que convergen múltiples intereses, por lo que el gobierno tradicional es insuficiente para responder a las nuevas demandas en la gestión ambiental. En este sentido, la teoría de la gobernanza propone un papel más importante para los actores sociales en la toma de decisiones, para una resolución más efectiva de los problemas ambientales. Este artículo se centra en las organizaciones de la sociedad civil (osc) de Ensenada, debido a su relevancia en el ámbito público y el valor ecológico de la zona. A través de una encuesta se caracterizaron 22 osc, sus participantes y su red de actores. Se encontró que existen tres grupos de osc centrados en la agenda de conservación y en la sustentabilidad urbanas.

Palabras clave: gestión ambiental, organizaciones de la sociedad civil, gobernanza, redes.
Abstract

The environment is a complex space where multiple interests converge, so the traditional government has been insufficient to respond to the new demands of the environmental management. In this sense, the theory governance suggests a bigger role for social actors in decision-making for a more effective resolution of environmental problems. This article focuses on the Civil Society Organizations (cso's) of Ensenada, due to its relevance in the public sphere and the ecological value of the area. Twenty two csos, its participants and the network of actors were characterized through a survey. It was found that three types of csos are focusing on the conservation agenda and urban sustainability.

Keywords: environmental management, civil society organizations, governance, networks.

Recibido el 20 de septiembre de 2013.

Aprobado el 27 de febrero de 2014.

* Estudiante en la maestría en Manejo de Ecosistemas de Zonas Áridas en la Universidad Autónoma de Baja California. Director de Tierra Colectiva: Ciudadanía, Género y Medio Ambiente, A. C. Correo electrónico: martinez.nain@gmail.com

** Doctorando en Gobierno y Administración Pública en el Instituto Universitario de Investigación Ortega y Gasset. Madrid, España. Correo electrónico: refugiochavez@gmail.com 


\section{Introducción}

Desde la década de 1980, las organizaciones de la sociedad civil (OSC) han cobrado un papel cada vez más relevante en los asuntos de interés público, que antiguamente se reservaban al gobierno y sus burocracias. En la actualidad, las OSC realizan denuncias, ponen temas de interés social en la agenda pública, desarrollan proyectos de colaboración con las instituciones gubernamentales, tejen redes transnacionales y realizan investigación. En general, revitalizaron la vida pública de las naciones y enriquecieron el debate democrático, y en un corto periodo se convirtieron en un actor con legitimidad propia proveniente del reconocimiento social.

La nueva dimensión de las osc en los asuntos sociales se explica desde acercamientos teóricos como la gobernanza y la participación ciudadana. En ellas se resalta que en las sociedades contemporáneas los asuntos posmateriales, como la inclusión de género, la democracia participativa, la agenda ambiental, la transparencia y el acceso a la información, ocupan un papel central que requiere de nuevos tipos de experiencia y conocimiento que no pueden ser satisfechos por las burocracias gubernamentales. Esto genera una mayor dependencia del gobierno de fuentes externas, las cuales, con frecuencia, son ocupadas por las osc (Peters y Pierre, 2005). De esta manera, se resalta que los actores sociales contienen recursos valiosos que pueden ser utilizados para el direccionamiento social. Por ello se promueven los procesos participativos como medio para incorporar las demandas, valores y preferencias sociales, y como fin, propiciando comunicación, flujo de información y aprendizaje entre actores (Turnhout, Bommely y Arts, 2010).

La participación ciudadana cobra un especial interés en el sector ambiental, debido a que se reconoce la complejidad de los problemas ambientales que se desarrollan en el interfaz de los procesos ecológicos, sociales, económicos y culturales. Esto genera una alta incertidumbre en la información científica, a la par de que existe una urgencia social para tomar decisiones políticas que pueden resultar riesgosas. De esta manera, se propone la conformación de una comunidad extendida de pares, donde todos aquellos afectados e interesados por una problemática o decisión, aporten su perspectiva y conocimiento en los procesos políticos para su integración con la información académica proveniente de 
diversas disciplinas (Funtowicz y Ravetz, 1993; Morse, Nielsen-Pincus, Force y Wulfhorst, 2007).

Por otra parte, en la ciudad de Ensenada las OsC ambientales son actores activos en el debate de la problemática local. Esto se debe al alto valor ecológico de la zona, la conformación de redes regionales e internacionales y el reconocimiento de la sociedad a su labor. Las osc en Ensenada se insertaron con éxito en procesos participativos frente a las instituciones gubernamentales y los actores económicos, convirtiéndose en interlocutores en la gestión de una agenda ambiental de impacto regional (Santos y Sánchez, 2007). El objetivo de esta investigación es describir a las organizaciones ambientales en relación con su composición, estructura y áreas de trabajo; las características de quienes pertenecen a ellas y la interrelación que existe entre las osc y otros actores. Con esta información se explorará el alcance de sus acciones en el ámbito público.

\section{Las organizaciones de la sociedad civil en la gobernanza del sector ambiental}

En este apartado se describe inicialmente el concepto de gobernanza, que establece la necesidad de incluir a todos los actores políticos en una sociedad a que participen en el proceso de dirección. A partir de él se retoma el concepto de sociedad civil, del que se deriva el de organizaciones de la sociedad civil, que después se utilizará para elaborar el análisis de las osc en Ensenada.

\section{Gobernanza}

La gobernanza es un nuevo proceso en la dirección política en el que hay un incremento en la interacción entre gobierno y actores sociales, lo cual genera un cambio del modelo clásico de gobernar caracterizado por una dinámica centralizada y "unidireccional" (del gobierno hacia la sociedad), a otro "bidireccional" donde el gobierno también se ve influenciado por actores sociales más autónomos, que a menudo se configuran como redes políticas (Aguilar, 2010). En este sentido, la gobernanza responde a 
diversos cambios en la sociedad, como las crisis financieras de las décadas de 1970 y 1980 que replantearon la viabilidad del Estado burocrático, la globalización, la liberación de los mercados, nuevas tendencias en la gestión pública que buscan incrementar la eficiencia y una mayor capacidad y complejidad de las sociedades (Concepción, 2010; Peters y Pierre, 2005).

En la implementación de las políticas públicas y el ejercicio de gobierno, la gobernanza no implica necesariamente una alta participación social o una distribución más equitativa del poder, lo cual depende en gran medida del contexto y el sector en cuestión. Sin embargo, la gobernanza sí tiene implicaciones en la manera en que se gestiona la participación ciudadana, en quienes intervienen en la toma de decisiones y en la elección de instrumentos políticos suaves basados en la información, el acuerdo y el mercado, sobre los instrumentos coercitivos o reglamentarios.

En la actualidad existen diferentes perspectivas teóricas y elementos de discusión sobre la gobernanza que se aglutinan principalmente en dos posiciones, una centrada en el Estado y en la implementación de nuevos mecanismos para el cumplimiento de sus funciones, como la conformación de redes, y otra enfocada en la sociedad, la cual considera que los actores sociales han adquirido mayor preponderancia en relación con el gobierno en la dirección social. No obstante la discusión académica, la teoría de la gobernanza permite analizar el papel de los actores sociales en los asuntos de interés público y abre la posibilidad de que actores diferentes al gobierno tomen un papel más activo en la resolución de problemas en común (Graham, Amos y Plumptre, 2003).

En este contexto, el creciente énfasis sobre la gobernanza en la gestión ambiental se debe a la complejidad que caracteriza a los problemas ambientales en los que confluyen procesos ecológicos, necesidades sociales, instituciones y relaciones culturales, lo cual incrementa la incertidumbre en la toma de decisiones y los costos derivados de ellas (Funtowicz y Ravetz, 1993). También se encuentra influenciado por enfoques emergentes en materia de conservación, en los que se revaloran las funciones ecológicas de los humanos y su capacidad para gestionar el riesgo (Ludwing, Mangel y Haddad, 2001).

Además, la política en este sector enfrenta diversos retos. Por ejemplo, los instrumentos de regulación que operan sobre el territorio en algunas 
ocasiones son contradictorios o de difícil interpretación y la reglamentación llega a ser percibida por la población como descontextualizada de la realidad, insuficiente, inflexible o injusta en las cargas económicas que infringe a algunos actores o sectores (Bobadilla, Álvarez, Ávila, Lara y Espejel, 2011). En este sentido, un error común es la falta de incentivos en las leyes, políticas y reglamentos para involucrar a la sociedad en los objetivos de la política ambiental (Abrams, Borrin- Feyerabend, Gardner y Heylings, 2003).

Debido a estos retos, se ha propuesto transitar de una política ambiental tradicional basada en la jerarquía y el control gubernamental, a otra con mayor participación de los actores sociales. Esto porque se reconoce que los procesos participativos tienen el potencial de generar aprendizaje a nivel comunitario, comunicar información entre actores, propiciar la resolución de conflictos, acordar acciones de colaboración entre los interesados e incorporar recursos económicos, humanos e informativos provenientes de los actores sociales para mejorar el alcance de la política ambiental (Lockwood, 2010; Turnhout et al., 2010).

\section{Conexión entre gobernanza y participación ciudadana}

a través de las organizaciones de la sociedad civil

A pesar de las dificultades terminológicas y de la ambigüedad que rodea a este concepto, la gobernanza representa una manera de expresar los límites del modelo tradicional de gobierno y la búsqueda de nuevas formas de concebir y de ejercer la autoridad pública. Más concretamente, el paradigma del nuevo gobierno relacional se fundamenta en el reconocimiento de un escenario caracterizado por una complejidad que viene motivada por dos elementos básicos: en primer lugar, por la diversidad implícita en la existencia de múltiples actores con recursos necesarios, actores que además incorporan al proceso político una variedad de valores, objetivos y preferencias; en segundo lugar, por la incertidumbre que provoca el cambio permanente, la erosión de las certezas cognitivas y la inestabilidad del conocimiento sobre las cosas (Espluga y Subirats, 2008, pp. 1-2). En ese sentido se retoma el concepto de sociedad civil y organizaciones de la sociedad civil bajo la necesidad de describir y abordar a la ciudadanía como uno de 
los actores que más interés debería tener en el proceso de gobernar, al ser estos sujetos el objetivo de las políticas elaboradas y potenciales agentes de cambio en las mismas.

\section{Conceptualizando a la sociedad civil y sus organizaciones}

El término castellano sociedad civil deriva del latín societas civilis (del sustantivo societas: cualquier sociedad o asociación de grupos o individuos, y el adjetivo civilis: referido a la sociedad de la ciudad) que significaba una sociedad ciudadana o de la ciudad; éste, a su vez, derivó del griego koinona politike, en el que koinona describe una sociedad cualquiera y politike una sociedad política, de la polis (ciudad actual) (Pavón y Sabucedo, 2009, pp. 65-66).

Existen muchas formas de abordar un concepto más amplio que el de gobernanza mismo, cada autor tiene una visión, a partir de la cual lo desarrolla en función de sus intereses, contexto, potencialidad, necesidades, etcétera. Cada uno de ellos condiciona sus relaciones y sus actividades. Sin embargo, en el presente texto no se esbozará un recuento de cada una de las variantes del concepto, pues no es el foco de atención de la gestión ambiental.

Basta mencionar un recuento histórico elaborado por Pavón y Sabucedo (2009), quienes revisan las distintas concepciones de la sociedad civil a lo largo de la historia: inician con Aristóteles y su concepción de la sociedad civil en la que los hombres se asocian de manera natural; continúan con Hobbes quien la entiende como una convención o acuerdo múltiple entre los ciudadanos; posteriormente analizan a Locke, Rousseau y Ferguson quienes distinguen una contingencia entre naturaleza/convención y guerra/paz; prosiguen con Kant, Fichte y Hegel que la explican desde la abstracción de las relaciones civiles (que no le pertenecen a nadie, son un resultado de todo lo que opera bajo ella), la formalización de relaciones sociales y la pasividad social, es decir, una sociedad civil que aunque constituida por relaciones internas propias es condicionada por la autoridad del Estado; respectivamente, en Tocqueville y Marx, la sociedad civil recupera la concreción material y la acción independiente cuando expresan la capacidad propia de acción y movimiento; y finalizan con Gramsci en donde la sociedad civil alcanza la concreción (la fusión entre Estado y sociedad) y el 
ideal (una hegemonía en la que el Estado no domina, sino que constituye). A esta revisión incorporamos la definición de Habermas (1998), en el que la sociedad civil es la ampliación del espacio de opinión pública.

Existen muchas otras versiones provenientes de distintos autores enmarcados en contextos muy particulares. Aunque algunos hablan de la "resurrección" de la sociedad civil a finales del siglo xx en distintas partes del mundo como consecuencia de fenómenos estrictamente políticos, ${ }^{1}$ en el análisis teórico la sociedad civil ha estado presente, en mayor o menor medida, a lo largo de la historia contemporánea (Garreton, 2005, p. 46). Hablar de su "resurrección” implica una muerte previa y se considera que ésta nunca ocurrió.

La presencia constante del concepto, menciona Vallespin (1996, p. 41), se debe al hecho de que es necesario atender dos de las grandes deficiencias que asolan las relaciones entre sistema político y sociedad: la ausencia de un sujeto unitario claramente delimitado y el déficit de integración normativa. La sociedad civil constituiría así un subterfugio a partir del cual la creciente diferenciación y fragmentación del sistema democrático puede ser esbozada dentro de una unidad social.

\section{Particularidad latinoamericana}

En el contexto latinoamericano (el caso mexicano es muy representativo en él), Garretón señala una particular dificultad en la asimilación de la sociedad civil como un tejido asociativo de contrapeso al Estado porque no se está ante sociedades organizadas desde abajo, desde los individuos o de sus asociaciones, que estructuran la autoridad del Estado, sino que éste es el que constituye a la sociedad, desde el principio simbólico de una nación a través de la política, institucional o movilizadora, más movilizadora que participativa. Así, la sociedad civil no se constituye como contrapeso al

${ }^{1}$ En Europa como respuesta a la crisis del Estado de bienestar; en los países comunistas como la gran vencedora del Estado totalitario y la causante de su colapso y derrota; y en América Latina con las expectativas incumplidas y los vacíos de la democratización política. Es decir, en el primer caso se trata de llenar un espacio político, en el segundo como agente de cambio y en el tercero como sustituto de los actores políticos clásicos en el proceso de democratización (Garretón, 2005, pp. 46-47). 
Estado sino como estructura asociativa autónoma, un conjunto de actores sociales con algún nivel de organización o masas movilizadas en torno a algún eje político, personal o institucional (2005, p. 47). Se agrega el hecho de que operan en contextos políticos dinamitados donde el centro de toma de decisiones, el Estado, pierde capacidades: el sistema democrático se vislumbra incapaz de organizar a la sociedad como espacio de constitución de sujetos y de toma de decisiones (2005, p. 57). Eso muestra la clara necesidad de reconstruir la polis o los Estados en los niveles local, nacional e internacional. La idea es entender a la sociedad civil como aquel conjunto de actores que contribuye específicamente a la reconstrucción de la polis y la ciudadanía, como aquel sujeto de demandas y proyectos que reconstituyen efectivamente el espacio donde la sociedad y el país se producen como tales.

\section{La sociedad civil: Acercamiento empírico}

Ante la variedad de términos y debido a que el concepto puede incluir un conjunto sumamente amplio de organizaciones con orígenes, objetivos y conformaciones distintos, es necesario precisar cómo entendemos a las organizaciones de la sociedad civil.

Andrew y Edwards (como se citó en Acuña y Vaccieri, 2007, p. 21) propusieron una definición que destaca atributos de la estructura y las funciones de las Osc. De acuerdo con ella, estas organizaciones son: formalmente organizadas, públicas (en el sentido de que sus objetivos deberían interesar a otras personas además de a sus miembros), pero privadas (institucionalmente independientes del Estado), autogobernadas (no gobernadas por el Estado), no distribuyen beneficios entre sus miembros (aunque puedan generarlos por la venta de bienes o servicios) y voluntarias.

A la definición anterior Acuña y Vacchieri (2007, p. 22) le agregan dos rasgos de función: la búsqueda de un cambio social o resistencia al mismo, y la apelación a algún argumento de interés público. ${ }^{2}$ Entendiéndolas

${ }^{2}$ Con esa ampliación se incluye a las organizaciones que desarrollan actividades de advocacy pero también las que hacen lobby, movilización, participación en espacios de consulta para el diseño de las políticas públicas y la colaboración en la implementación y en la evaluación de políticas públicas. 
finalmente como "organizaciones que desarrollan estrategias respaldadas en argumentos de interés público para promover o resistir cambios sociales que, si se implementaran, entrarían en conflicto con los intereses o valores sociales, culturales, políticos o económicos de otros grupos u organizaciones".

En ese sentido, son ejemplos de osc las organizaciones no gubernamentales, las organizaciones no lucrativas, las organizaciones comunitarias de base (como las organizaciones barriales, deportivas, etc.), los clubes, los grupos religiosos, los sindicatos, los colegios profesionales, las fundaciones, think tanks, etcétera.

\section{Las osC como herramienta}

de mejora en la gestión ambiental

Una vez que la consolidación de las instituciones ha dejado de ser el problema, ${ }^{3}$ los gobiernos deben operar en un escenario cada vez más complejo $^{4}$ donde se hace presente una multiplicidad de actores con valores objetivos y preferencias particulares (Dukes, 1996); al mismo tiempo, los problemas son más amplios, dinámicos e interdependientes y, por ende, difíciles de abordar, definir y segmentar (Ballester, Espluga y Subirats, 2008).

En esas nuevas condiciones, el papel activo de los actores sociales y de su participación crea una conexión permanente entre el gobierno y los gobernados permitiendo una mejor comprensión de los problemas que

${ }^{3}$ Las elecciones son una muestra clara, sus resultados consagran autoridades legítimas, pero al mismo tiempo ellas son vistas como actos en donde intervienen factores aleatorios, lo que incentiva el humor ciudadano de independencia y la idea de que la expresión legítima de su voluntad no se agota en el pronunciamiento electoral (Chereski, 2005, p. 30).

${ }^{4} \mathrm{Al}$ respecto, Dukes (1996, p. 17) señala entre los factores de complejidad los siguientes: crecimiento del aparato administrativo estatal; cambios en el panorama legal en áreas críticas de las políticas (especialmente ambientales); el crecimiento de problemas públicos persistentes con mayor incertidumbre y complejidad científico-técnica; causalidad múltiple, resistencia a las soluciones unilaterales; ampliación de las jurisdicciones políticas existentes; y el reconocimiento de la inhabilidad de las prácticas e instituciones existentes para atender estas demandas. 
le preocupan a la sociedad. Esto da la oportunidad de que todas las partes trabajen cooperativamente hacia la toma de decisiones más razonadas (producto de un mayor consenso).

Para Putnam (1995), la participación ciudadana ha desempeñado un papel central en los procesos democratizadores de muchos países. Especialmente en democracias en construcción, el fomento a la participación debe entenderse como una vía obligada para fortalecerlas, incluyendo a la ciudadanía en las acciones de instituciones que no les ha incluido hasta el momento. Su objetivo es doble: incorporar las demandas de la población al quehacer gubernamental y asegurar que éste sea vigilado tanto por las propias instituciones que tienen dicha encomienda como por las diferentes agencias de la sociedad civil. Al completarse el círculo de la participación de los ciudadanos (elección de representantes y control sobre su desempeño), se estrecha la comunicación entre la sociedad y el poder (Peschard, 2006). En todos los países democráticos que veían deteriorar su legitimidad en las instituciones públicas, la ciudadanía reflexiva y crítica pudo revitalizarla a través de su participación (Font, Gomá y Jarque, 2000).

En ese sentido, muchos autores concuerdan que con el envolvimiento ciudadano activo en la gestión gubernamental, la gobernanza que emergerá será más democrática y efectiva, las políticas podrán ser aterrizadas de manera más realista sobre las preferencias de los ciudadanos, conseguirá más simpatía y apoyo en decisiones difíciles; asimismo, brindará transparencia a los gobiernos y permitirá evitar comportamientos corruptos, clarificará las responsabilidades y facilitará la eventual aplicación de sanciones en caso de conductas reprochables (Putnam, 1995; Day, 1997; King, Feltey y Susei, 1998; Cabrero, 2000; Di Paola, Sangalli y Caorsi, 2011).

En la gestión gubernamental, el ramo ambiental, particularmente, y su construcción de soluciones requiere de conocimientos aportados por expertos, pero también debe incluir los valores, las normas y las expectativas de los actores sociales de la comunidad, pues sin ellos, en un trabajo en red, será imposible valorar la repercusión de los problemas y sus soluciones. La ausencia de dicha red supondría una falta del proceso de participación que se quiere poner en marcha (EAPN, 2010, p. 73). Mientras que la participación genera un aumento de la sensibilidad y representa, al mismo tiempo, un medio fundamental para lograr el cambio social de actitudes y 
de mentalidad, así como la re-construcción de los espacios habitables y el territorio en general.

Sin embargo, los procesos participativos en materia ambiental suelen presentar dificultades de entendimiento entre políticos, técnicos y ciudadanos, poniendo de manifiesto las diferencias y disociaciones entre estos actores y sus espacios (Gutiérrez y Garrido, 2006); como consecuencia, según Irvin y Stansbury (2004, pp. 56-60), los procesos pueden:

- Ser costosos, al menos más caros que la toma de decisiones unilateral y jerárquica en las administraciones públicas.

- Presentar dificultad para considerar todas las voluntades ciudadanas: no hay garantía de que cada participante represente una influencia real para su comunidad.

- Ser complacientes. Trabajar en las decisiones e implementación de las políticas conlleva una serie de reuniones, una actividad que los ciudadanos prefieren evitar.

- Ya que los participantes no reciben un salario por participación, los comités pueden ser dominados por partidarios que ven fuertemente afectado su modo de vida por las decisiones a tomar o por aquellos que viven con holgura económica y que pueden participar regularmente.

- Distanciar gobierno-gobernados. Si los participantes son engañados pensando que sus decisiones se aplicarán y éstas son ignoradas o simplemente subestimadas, con el tiempo el resentimiento será evidente.

- Aunque una ciudadanía activa puede romper la parálisis política, puede también ratificar decisiones egoístas que favorezcan a los miembros más poderosos e influyentes en lugar de al público en general.

En este contexto en el que la participación ciudadana directa aún enfrenta muchas barreras (y pareciera evidente que no es la panacea para resolver todos los problemas que enfrenta la sociedad), es imprescindible buscar nuevas formas de facilitar a los ciudadanos su inclusión en la toma de decisiones. Entidades colectivas como las osc pueden permitir que muchas de las barreras arriba mencionadas se superen puesto que: 
1. Participan en organismos e instituciones públicas, en espacios institucionales: consejos, foros, plataformas, entre otras actividades, desde donde pueden ejercer, según su grado de influencia y posibilidades, su participación social y ciudadana.

2. Cuando no todos tienen sus derechos como ciudadanos y ciudadanas les está vetada la participación ciudadana formal y política, en estos casos servirán para generar conciencia sobre la exigencia en la garantía de los derechos que carecen.

3. En el desarrollo de las políticas ambientales, la mayoría de las OSC desempeñan, entre otros, un papel como mediadoras o prestadoras directas de servicios (y en muchas ocasiones también de bienes) dentro de las acciones contempladas.

4. La participación en, y con OsC produce el capital social y eficacia institucional, y algunas de ellas pueden generar compromiso cívico y promover democracias eficaces, tanto por los recursos que movilizan como por los valores y las actitudes que promueven.

5. Las organizaciones constituidas aumentan la incidencia sobre las decisiones políticas, éstas pueden aportar continuidad en los procesos sociales que pretenden.

6. Su función educadora hacia dentro y fuera genera confianza en los valores democráticos y las instituciones que los representan. Cuentan con elementos de socialización que pueden actuar hacia la formación en valores de solidaridad, cooperación o responsabilidad colectiva.

La participación de las personas a las que se dirigen es uno de los retos de las OsC, pero para avanzar en las barreras que presenta la participación ciudadana directa es necesario descomponerla y atenderla de dos formas: por un lado, visibilizar y transformar a las personas en "participantes" dentro de la organización y sus acciones; el segundo reto sería conseguir que los participantes se reconozcan y sean reconocidos como "agentes de transformación social", en relación con la causa de la acción, el contexto socio-ecológico en el que se encuentran y su vinculación con la institución o política pública responsable (EAPN, 2010, p. 28). El papel como agentes intermedios es clave en la consecución de los retos y para derribar muchas de las barreras enfrentadas, así como para ampliar los 
niveles de involucramiento ciudadano en el corto y mediano plazos y mejorar la calidad de vida (y del entorno que habitan) en el largo plazo.

\section{Antecedentes}

\section{La sociedad civil en México y el surgimiento de las organizaciones ambientales}

El carácter organizado de la sociedad civil en México puede rastrearse desde el periodo colonial en las agrupaciones de carácter religioso que atendían necesidades no satisfechas de la población en condiciones de vulnerabilidad, debido a la inexistencia o insuficiencia de la política gubernamental. Sin embargo, la sociedad civil con características modernas surge hasta la década de 1970, vinculada a las universidades, grupos eclesiásticos, movimientos sociales y agrupaciones de izquierda. Así, en la década de 1980, con el fracaso del modelo de sustitución de importaciones y ante desajustes económicos críticos, la labor de la sociedad civil cobró una mayor relevancia adquiriendo legitimidad en su actuación y prestigio frente a la sociedad (Reyes, 2006).

En el mismo periodo surgen en México las organizaciones ambientales modernas influenciadas por la creciente preocupación de los problemas ambientales, el interés por la calidad del aire en el Valle de México, la conformación de un marco institucional para la gestión ambiental y el Informe Brundtland "Our Common Future" que proponía la sustentabilidad como un tipo de desarrollo que integra los valores económicos, sociales y ambientales. Estas agrupaciones organizan sus trabajos en torno a la agenda internacional (conservación y contaminación), pero incluyen a movimientos agrarios, indigenistas y grupos en favor de la mejora de las condiciones de vida de la población urbana (Durand, Guzmán y Génet, 2011), formando dos corrientes: los grupos conservacionistas y las organizaciones avocadas a los problemas derivados de la relación sociedadambiente (Alfie, 2002).

Debido a la amplitud de la agenda ambiental, las diferentes escalas de gestión de las problemáticas de interés y la diversidad en la composición y estructura de los grupos, las organizaciones ambientales tienen 
por finalidad influir en el ciclo de las políticas públicas y modificar la relación entre la sociedad y el ambiente. En este sentido, los grupos actúan en las instancias gubernamentales y en el ámbito político, en los procesos y proyectos de los actores económicos y frente a la sociedad en general para difundir problemáticas, generar conciencia y modificar actitudes (Alfie, 2002). Para ello, realizan denuncias, cabildeo y gestión, proyectos directos con las comunidades, promueven la organización social, desarrollan campañas de difusión y prestan servicios profesionales (Keohame y Nye, 2000).

\section{Las organizaciones ambientales en Baja California}

En Baja California, las primeras organizaciones ambientales surgen en la década de 1980 vinculadas a grupos académicos interesados por la conservación de los ecosistemas y la degradación del ambiente, y la ciudadanía en general preocupada o afectada por la contaminación generada por la industria, en especial las maquiladoras, los asentamientos irregulares y la vulnerabilidad de la población, así como el déficit de servicios públicos (Reyes, 2006).

La problemática ambiental en la región se caracteriza por su condición de frontera con Estados Unidos de América, con quien comparten ecosistemas y cuencas hidrológicas, además de un intenso intercambio económico y social, lo cual produce problemas e intereses compartidos. En este sentido, los grupos ambientalistas desde sus inicios buscaron generar vínculos con las organizaciones ambientales de Estados Unidos y, por ello, fueron pioneros en la conformación de redes binacionales a escala nacional (Alfie, 2001; Velázquez, 2007).

A raíz de la negociación del Tratado de Libre Comercio de América del Norte (TLCAN), las OSC ambientales generaron alianzas y agendas compartidas en ambos lados de la frontera que impulsaron la conformación de una política ambiental regional e instituciones para su gestión; por ejemplo: el Acuerdo de Cooperación Ambiental de América del Norte (ACAAN) en 1993, la conformación de la Comisión de Cooperación Ecológica Fronteriza (Cocef), el Banco de Desarrollo de América del Norte (BDAN) y, en 1996, el Programa Frontera Xxi para la promoción del desarrollo sustentable. Durante este periodo se conformó la mayoría de los grupos ambientalistas en la región. 
En 2008 Moreno estimaba en 35 el número de Osc ambientales en Baja California, cuya edad promedio era de 11.3 años de antigüedad, 76.5\% era Asociaciones Civiles (A. C.) y 23.5\% Sociedades Civiles (S.C.). De estas organizaciones, $50 \%$ no contaba con recursos para el financiamiento de sus actividades o accedía a ellos esporádicamente, por lo que el número de integrantes era reducido aunque más profesionalizado en relación con OSC de otras temáticas y con una activa participación de mujeres (Reyes, 2006). Las OSC enmarcaban sus proyectos en la promoción del desarrollo de las comunidades, mediante programas educativos y un importante componente de investigación y diagnósticos.

\section{Proceso de participación e incidencia de las osc ambientales en Ensenada}

Además de los proyectos y programas que cada osc desarrolla, la red de organizaciones ambientales respondió en momentos coyunturales frente a instancias gubernamentales y la iniciativa privada articulando redes de colaboración, realizando cabildeo y haciendo uso de mecanismos de participación previstos en la legislación ambiental, lo cual representa un aprendizaje social de la comunidad. A continuación se mencionan algunos.

Intervinieron de manera activa en las modificaciones realizadas a la Ley de Equilibrio Ecológico y Protección al Ambiente de Baja California (1992) para su adaptación (conforme a la Ley General del Equilibrio y Protección al Ambiente [LGEEPA] de 1996) y publicación en 2001 (Moreno, 2008; Reyes, 2006).

También participaron contra la instalación de la planta de almacenamiento y regasificación de gas natural licuado de Energía Costa Azul S. A. de R. L. de C.V., filial de Sempra Energy Global Enterprise Group, a 27 kilómetros al norte de la ciudad de Ensenada, para el abastecimiento de gas licuado al sur de California. Aunque el proyecto fue rechazado en la comunidad, debido al valor ecológico de la zona y a los escasos beneficios que generaría en la región, la propuesta salió adelante; sin embargo, los grupos ambientalistas, a través del mecanismo de Consulta Pública previsto en la LGEEPA, lograron condicionar su funcionamiento y fortalecer la articulación ciudadana (Santos y Sánchez, 2007). 
Por otra parte, en 2002 comenzó la discusión sobre la construcción de un puerto de altura en Punta Colonet a $130 \mathrm{~km}$ de Ensenada, previsto como uno de los mayores puertos que atendería el creciente flujo comercial de contenedores en el Pacífico y competiría con los puertos de Los Ángeles y Long Beach, California. El proyecto fue presentado de manera formal por el gobierno federal en 2008, sin embargo, la recesión económica en Estados Unidos, iniciada ese mismo año, detuvo su concreción, emergiendo esporádicamente en la agenda pública local.

Las osc también centraron su interés en el Cañón de Doña Petra, considerado la última zona arbolada natural dentro de la ciudad y de interés ecológico por su vegetación riparia. No obstante, enfrenta fuertes presiones para el desarrollo de proyectos habitacionales y comerciales en la zona. Por ello, las organizaciones realizaron una campaña de presión en los medios locales que logró su declaración como área protegida municipal. ${ }^{5}$

En 2008 se presentó el Manifiesto de Impacto Ambiental (MIA) ante la Secretaría de Medio Ambiente y Recursos Naturales (Semarnat) para la construcción de la Marina Porto Hussong (un desarrollo de 299946.59 $\mathrm{m}^{2}$ con la construcción de un rompeolas de $866 \mathrm{~m}$ de longitud que le permitirá atender embarcaciones de hasta $75 \mathrm{~m}$ de eslora, consideradas megayates, provenientes principalmente de California) dentro de la zona urbana de Ensenada, sobre "Playitas", una playa de uso histórico para la población local. Debido a la pérdida de la playa y el paisaje para la ciudad, entre otras graves consecuencias, las osc consiguieron una Consulta Pública el 29 de mayo de 2008. A partir de ella, lograron que la Semarnat negara la autorización del mia para la construcción de la marina.

Otro proceso de participación ha girado en torno a la protección de la Lagunita El Ciprés, considerada el último humedal en la zona urbana y de interés biológico por la presencia de aves migratorias compartidas con California. Pese a esto, se encuentra ubicada en un área de creciente desarrollo inmobiliario y comercial, y en 2007 se inició la construcción de un complejo inmobiliario para la atención de la demanda residencial en California. Este suceso generó protestas y movilizaciones en su contra, que no lograron impedir la obra. En la actualidad una red de 10 organizaciones tratan de impedir la construcción de una planta desaladora de agua de mar en la misma área.

${ }^{5}$ Aunque continúa la lucha por la conservación de la zona debido a la poca claridad de los objetivos de la declaratoria. 
Además, las Osc ambientales se involucraron en la promoción de una playa pública municipal, debido a la pérdida de acceso a la costa por parte de la ciudadanía frente a los desarrollos turísticos, que se concretó en 2009. También impulsaron la certificación de la playa Lengüeta Arenosa de Punta Banda (2012) y han dado seguimiento a diversos proyectos inmobiliarios y turísticos en la región.

\section{Contexto socioecológico}

La ciudad de Ensenada es la cabecera del municipio de Ensenada, el de mayor extensión territorial (con 52510712 km², 74\% del estado de Baja California y $2.6 \%$ del territorio nacional) y de mayor frente litoral (con 1042 km en el Golfo de California y el Océano Pacífico) en México (Imip, 2007). Por otra parte, en las últimas décadas la ciudad presentó un rápido crecimiento impulsado por la migración; según datos del Instituto Nacional de Estadística y Geografía (INEGI), la población se incrementó de 169426 habitantes en 1990, a 279765 en 2010.

Sus principales actividades económicas son la industria manufacturera que aporta $38.5 \%$ del Producto Interno Bruto (РІв), seguido del sector terciario con $32.1 \%$, y el primario con $9.1 \%$. Asimismo, integra, junto con Rosarito y Tijuana, un corredor costero donde se encuentran los principales asentamientos humanos y la actividad industrial en la región, vinculado a la economía de California, Estados Unidos.

Además, la ciudad tiene un grado promedio de escolaridad alto de 10.14 (INEGI, 2010) y es reconocida por su contribución al desarrollo de tecnología e investigación científica con instituciones académicas como el Centro de Investigación Científica y Educación Superior de Ensenada (CICESE), los centros de Investigación en Nanociencias y Astronomía de la Universidad Nacional Autónoma de México (UNAM) y el Instituto de Investigaciones Oceanográficas (IIO) de la Universidad Autónoma de Baja California (UABC).

En relación con sus condiciones ambientales, la región tiene un clima mediterráneo con escasas precipitaciones invernales entre $200 \mathrm{~mm}$ y 400 $\mathrm{mm}$, con veranos secos y cálidos, y al sur y este del municipio, un clima seco. Pertenece a la Provincia Florística Californiana, compartida con el noroeste del estado y gran parte de California, representada por tipos de 
vegetación como bosque de coníferas, chaparral, matorral costero, marismas y dunas; al sur, corresponde a la Provincia Florística XerofíticoMexicana, compartida con las regiones desérticas de la península de Baja California, Sonora y el suroeste de Estados Unidos. Al ser una zona de ecotono entre dos grandes provincias florísticas, en la región se encuentra un número de endemismos inusual para una zona continental, lo cual le confiere un alto valor ecológico. Además, el noreste de la península, junto a California, es considerado como un hotspot debido a la pérdida de suelo natural por la expansión de las zonas urbanas, la fragmentación de los ecosistemas derivada de la construcción de carreteras y la contaminación (Myers, Mittermeier, R., Mittermeier, C., Da Fonseca y Kent, 2000).

En este sentido, se realizaron diversas declaratorias de Áreas Naturales Protegidas (ANP) que representan alrededor de $60 \%$ del territorio continental; también se ejecutaron cuatro declaratorias de Sitios Ramsar y, reconocidas por la Comisión Nacional para el Conocimiento y Uso de la Biodiversidad (Conabio), diversas Regiones Prioritarias para la Conservación de la Biodiversidad, Regiones Marinas Prioritarias, Regiones Hidrológicas Prioritarias y Áreas de Importancia para la Conservación de Aves (AICAS).

En este contexto socio-ecológico, las osc ambientales de la ciudad de Ensenada son actores emergentes con una participación cada vez más relevante en el debate de los temas de interés público de la localidad; sin embargo, no existe información que permita determinar el impacto local y regional de su labor. Por lo que el objetivo de esta investigación es describir a las organizaciones ambientales en relación con su composición, estructura y áreas de trabajo; las características de quienes pertenecen a ellas y la interrelación que existe entre las OsC y otros actores. Con esta información se explorará el alcance de sus acciones en el ámbito público.

\section{Metodología}

Para cumplir el objetivo de la investigación se desarrolló una encuesta compuesta por cuatro apartados:

1. Caracterización general de la organización. En él, se trató el origen de la organización, su misión y visión, los temas de interés, el tipo de acciones 
que realiza, las fuentes de financiamiento y el proceso de toma de decisiones, entre otros.

2. Los participantes. Se exploraron las características de los integrantes de las diversas organizaciones.

3. Interacciones de las OSC. Se analizaron las relaciones que establecen las organizaciones con otros grupos y actores sociales.

4. Debido a que existen diversos registros oficiales para las osc, a que su inscripción es de carácter voluntario y a que algunos grupos que trabajan activamente no se encuentran constituidos legalmente, se determinó el número de organizaciones por consulta directa de los activistas, encontrando un total de 22 organizaciones.

La encuesta se implementó de manera directa entre el 9 de enero y el 20 de diciembre de 2012, concertando una cita con la dirección de la organización. Un total de 19 organizaciones aceptaron responderla. En el caso de las tres organizaciones que no respondieron la encuesta, se utilizó información documental para su caracterización, principalmente la consulta de sus sitios oficiales. Por otra parte, el estudio de la interacción entre los actores fue utilizando el programa Gephi 0.8.1 beta que permite el análisis de redes, la conectividad entre sus elementos y la detección de subgrupos por similitud entre los individuos.

\section{Resultados}

\section{Las osc ambientales y sus actividades}

En la ciudad de Ensenada existen 22 organizaciones ambientales, siete de ellas evocan sus labores a la conservación y 15 tienen por objeto de interés la sustentabilidad y calidad de vida, principalmente a nivel urbano (Anexo 1). Por el ámbito de sus acciones, $55 \%$ de los grupos trabaja a escala local, $27 \%$ regional, $14 \%$ binacional y $5 \%$ nacional. Además, $59 \%$ de ellas tiene una conformación reciente entre el periodo 2008-2011 (figura 1); en este sentido, encontramos dos grupos de organizaciones: las conservacionistas, con más antigüedad, y las que dirigen sus esfuerzos a la sustentabilidad, de reciente creación. 
Figura 1. Conformación de osc ambientales en Ensenada, y número de organizaciones conservacionistas y de sustentabilidad

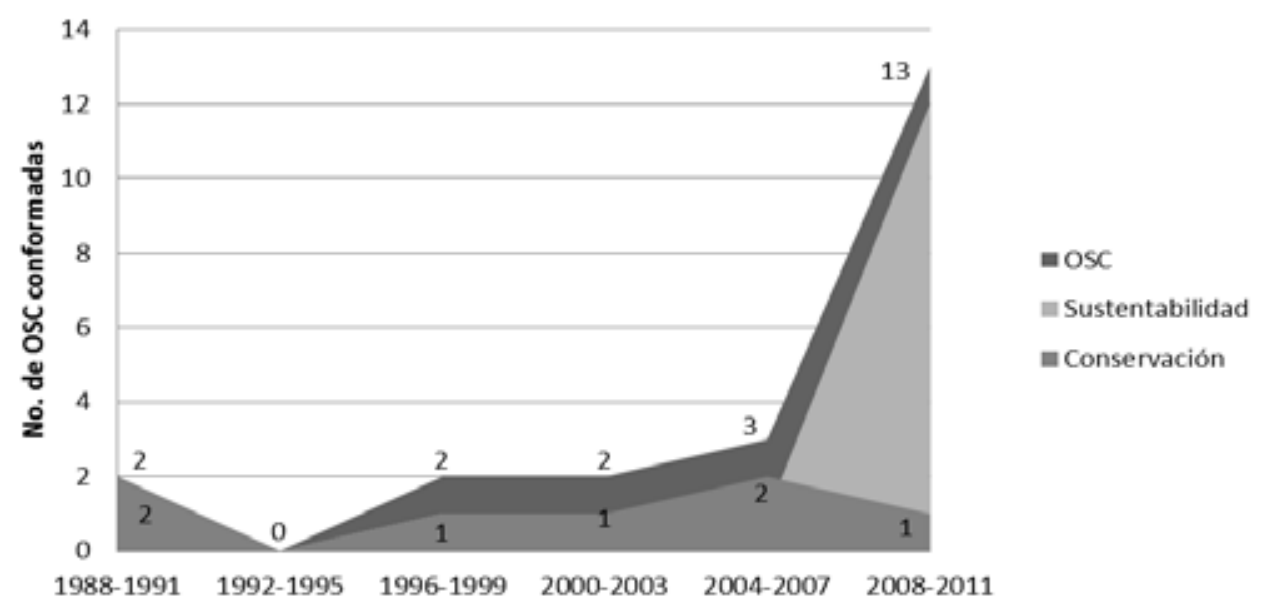

Fuente: Elaboración propia.

La población objetivo del $50 \%$ de las osc ambientales es de carácter general, sus actividades no están destinadas a un grupo o sector particular, y sus acciones y técnicas no se encuentran diferenciadas. Otro $11 \%$ trabaja con niños, adolescentes y jóvenes, y para ello realizan colaboraciones con madres, padres, líderes comunitarios, urbanos y rurales, educadores de preescolares comunitarios y demás. Otro $11 \%$ trabaja con la población del sector primario, principalmente pescadores y ejidatarios, y comunidades indígenas; las técnicas usadas por estas organizaciones pueden incluir desde capacitación, asistencia técnica, insumos y materiales, investigaciones, asesoría legal y técnica, fortalecimiento, etcétera. Tres bloques de osc, en igual proporción (7\%), trabajan enfocando sus actividades a los distintos niveles del gobierno (local, estatal y nacional), a las mujeres y a estudiantes de distintos niveles académicos, respectivamente. Otros dos grupos, de $4 \%$ cada uno, realizan evaluaciones sobre la calidad y transparencia de los servicios de otras organizaciones, y trabajan con poblaciones de escasos recursos económicos y que padecen la falta de acceso a servicios de salud, educación y vivienda. 


\section{Grado de organización de las osc}

En torno a la organización interna de los grupos, $27 \%$ no se encuentra constituido legalmente, $73 \%$ adopta la figura de A. C. y sólo ocho cuentan con la Clave Única de Inscripción (Cluni) del Registro Federal de Organizaciones de la Sociedad Civil, requisito para el acceso al financiamiento proveniente del gobierno federal. Únicamente $41 \%$ de las OsC posee oficinas o programas permanentes, el resto trabaja de manera esporádica o temporal.

En relación con el proceso de dirección, en 59\% de las OSC, aunque existan cargos formales, las decisiones se toman en procesos de diálogo y consenso continuos entre los participantes; mientras que en $41 \%$ se presenta una clara jerarquía y delimitación de responsabilidades, por lo que el proceso de toma de decisiones se realiza de manera vertical.

En lo que respecta al financiamiento, los dos subgrupos de OSC ambientales tienen características diferentes. En el caso de las organizaciones que trabajan temas de sustentabilidad y calidad de vida a escala urbana, dependen en gran medida de las aportaciones que realizan los socios y la población, que por lo general se traducen en trabajo voluntario y donaciones en especie; por ejemplo, $100 \%$ de los recursos de Transición Ensenada, Grupo Pro Ciclo Va y Surf-Ens provienen de sus socios e integrantes. Por otra parte, los grupos conservacionistas tienen como principal fuente económica los recursos internacionales; por ejemplo, $90 \%$ del presupuesto de costasalvaje y Pronatura Noroeste proviene de financiamiento internacional, como se observa en la figura 2, donde además se destaca la baja aportación de recursos gubernamentales que reciben ambos grupos.

El grupo de osc conservacionistas destaca por desarrollar planeación y presupuestos anuales para alcanzar sus objetivos, mientras que las organizaciones de sustentabilidad urbana implementan proyectos o acciones específicas y, mayoritariamente, su planeación es parcial o no existe, ${ }^{6}$ como se muestra en la figura 3. Dentro de los grupos, $32 \%$ efectúa diagnósticos

${ }^{6}$ Acción: es una actividad puntual; Proyecto: es un conjunto de actividades planeadas en el corto plazo, con un presupuesto delimitado, que se enfoca al alcance de un objetivo específico; Programa: es un conjunto estructurado de estrategias, medios y metas para alcanzar objetivos en el mediano plazo, que permite orientar las actividades de una organización. 
Figura 2. Comparativo entre fuentes de financiamiento de organizaciones conservacionistas y grupos de calidad de vida y sustentabilidad urbana (\%)

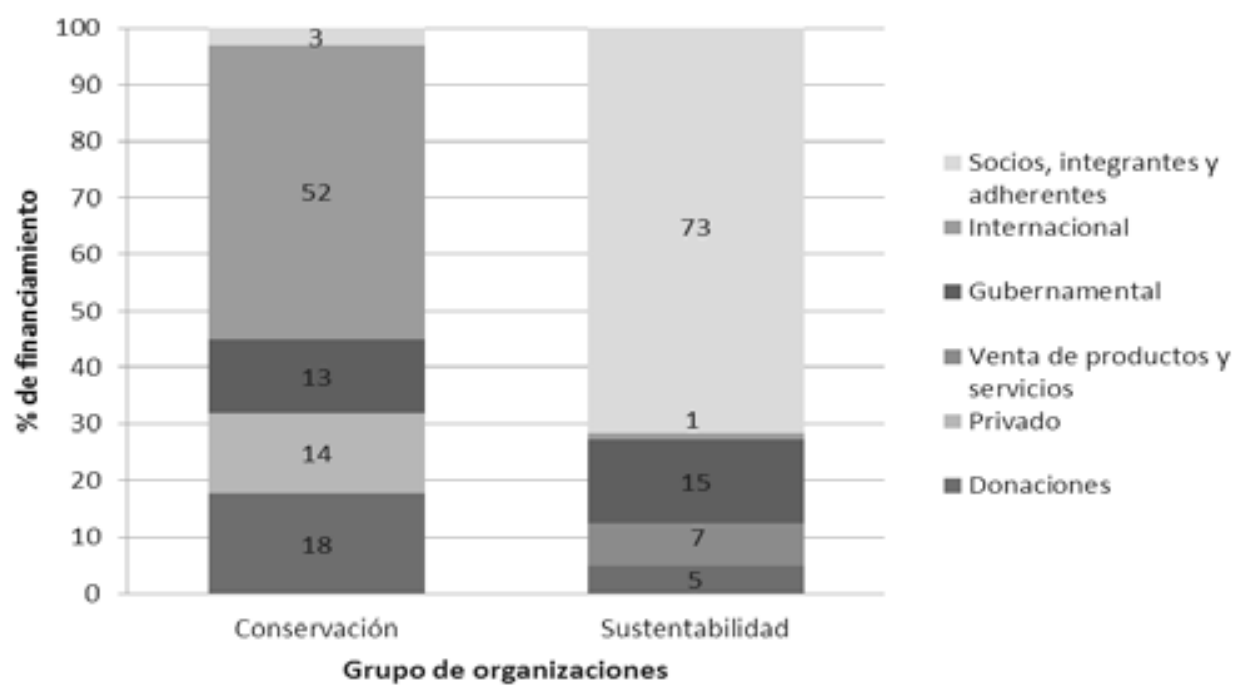

Fuente: Elaboración propia.

Figura 3. Grado de planeación de las osc y alcance de las actividades que realizan $(\%)$

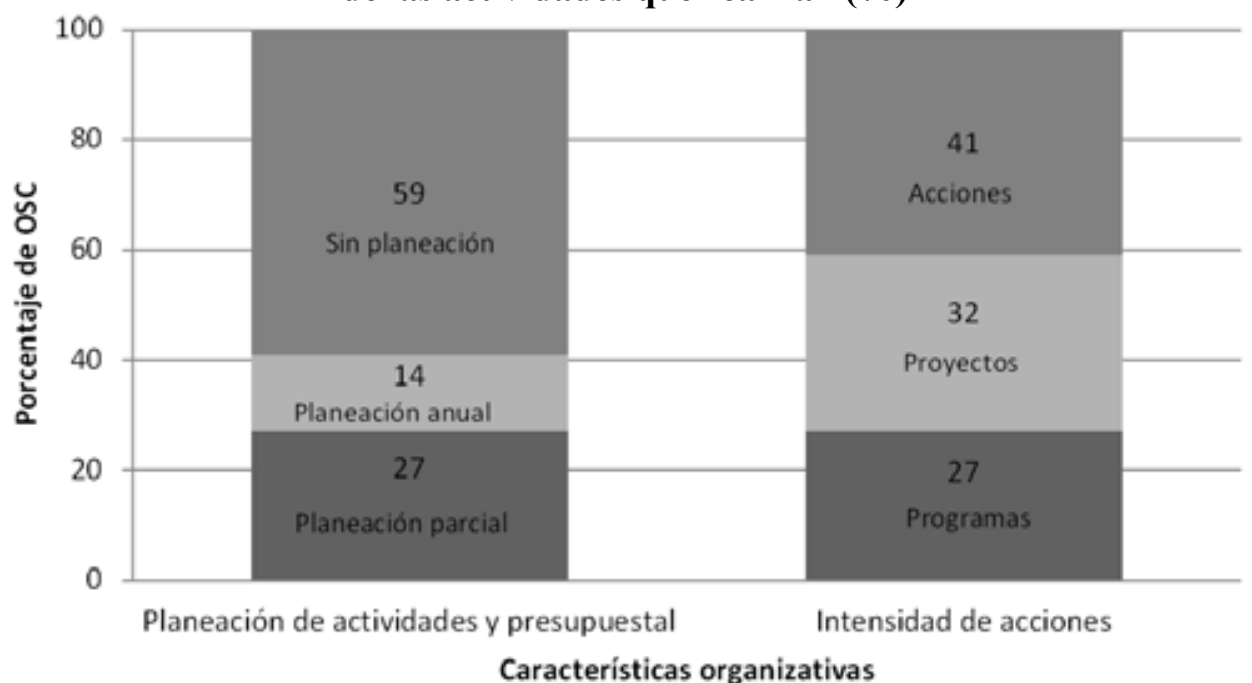

Fuente: Elaboración propia. 
o investigación, principalmente las conservacionistas y Tierra Colectiva: Ciudadanía, Género y Medio Ambiente, que realiza investigación en el área de la participación ciudadana.

\section{Características de los participantes}

Se estima que en las osc ambientales al menos 359 personas participan bajo diferentes esquemas de colaboración (mesa directiva, consejo directivo, voluntariado o personal técnico), de los cuales Pronatura y 4 Patas son las organizaciones con mayor número de participantes, a la vez que representan los extremos de dos situaciones diferentes: en el caso de Pronatura, se trata principalmente de personal técnico con una alta especialización, contratado para desarrollar las labores de conservación; y en 4 Patas, de un grupo de alrededor de 50 ciudadanos que realizan aportaciones mensuales para la manutención de sus actividades y trabajo voluntario. De entre las personas que participan, 147 trabajan de manera periódica en las organizaciones, y se estima que 97 reciben una compensación económica por su trabajo. Como características, las personas que trabajan en las osc tienen un nivel educativo alto y existe una alta participación de mujeres y de jóvenes menores de 29 años (véase figura 4).

\section{Características de la red de osc ambientales}

El análisis de modularidad muestra que existen tres subgrupos de organizaciones dentro de la red (véase figura 5).

Las organizaciones conservacionistas (Pronatura Noroeste, COSTASAlvaje, Grupo de Ecología y Conservación de Islas, entre otras): se caracterizan por la endogamia de sus relaciones que establecen principalmente entre ellas, pero también con OSC nacionales e internacionales. Otra característica es que gestionan su agenda principalmente con el gobierno federal, además de mantener pocos vínculos con las organizaciones de calidad de vida y sustentabilidad urbana.

Las osc de sustentabilidad urbana y calidad de vida con mayor antigüedad como Haciendo lo Necesario, Comité Ecológico Chapultepec y 
Figura 4. Composición por edad, sexo y grado de escolaridad, de las personas que trabajan en las osc ambientales

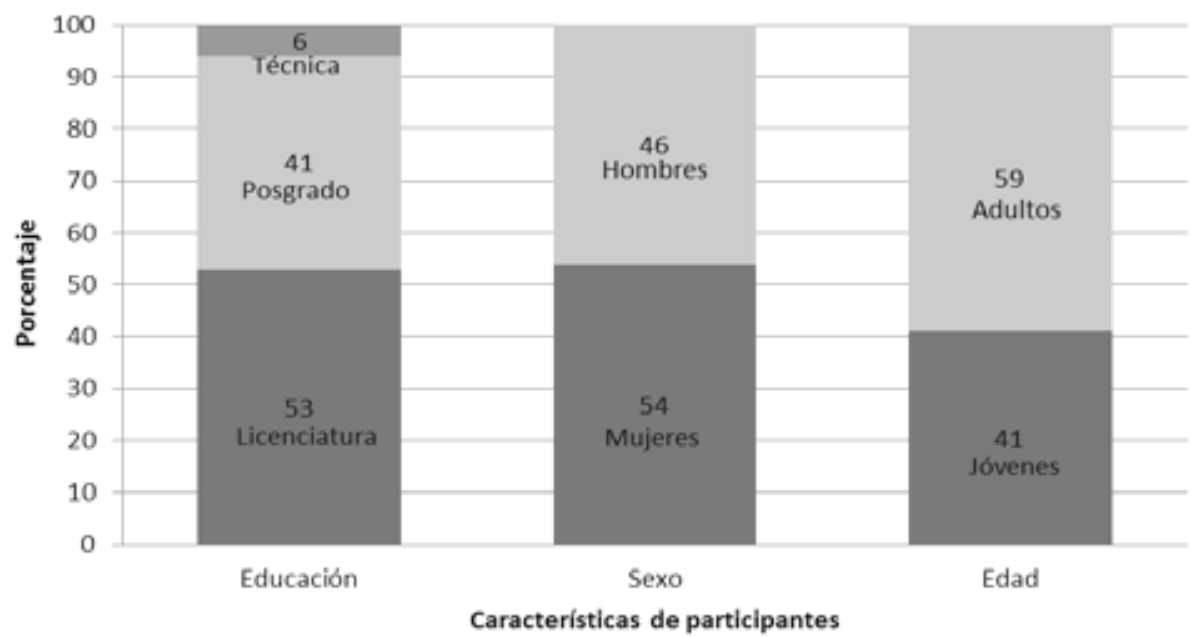

Fuente: Elaboración propia.

Figura 5. Red de osc ambientales y su interacción con diferentes actores*

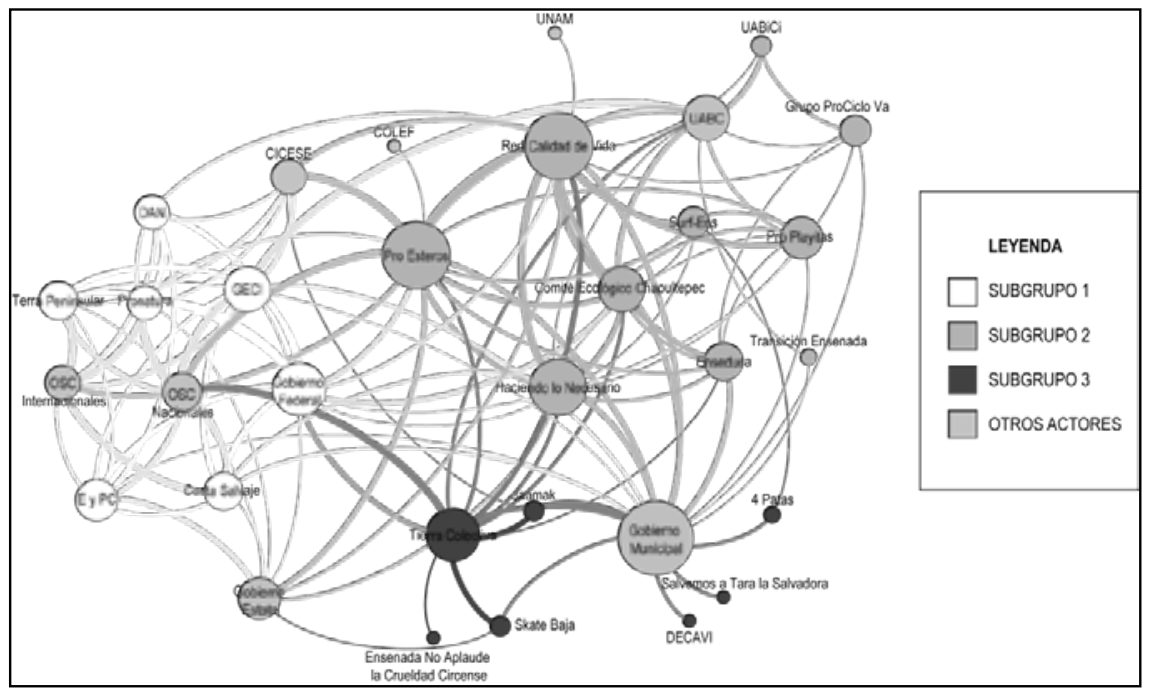

* El tamaño de los actores fue asignado por el número de interacciones (entre más interacciones mayor tamaño), y los colores describen los subgrupos por similitud en las características de las osc y los actores externos (gubernamentales, OSC nacionales y extranjeras, e instituciones académicas).

Fuente: Elaboración propia. 
Pro Esteros (aun cuando es una organización de conservación, tiene más afinidad a este grupo): sus interacciones se dan esencialmente entre ellas a través de la Red Calidad de Vida y gestionan su agenda principalmente a escala local con el gobierno municipal y estatal.

El tercer grupo está conformado por organizaciones orientadas a la sustentabilidad y calidad de vida urbanas de reciente composición, como Salvemos a la Diosa Tara, Jamaak Escuela Verde y Tierra Colectiva: Ciudadanía, Género y Medio Ambiente, etcétera; estas osc trabajan temas diversos, sin embargo, tienen como característica compartida la gestión de su agenda en el ámbito municipal y una baja interacción con otros actores.

Por otra parte, todas las organizaciones tienen por lo menos algún tipo de interacción o convenio con otra osc local, entidad gubernamental, organizaciones nacionales, instituciones académicas u OSC internacionales. Existen por lo menos 216 relaciones, de éstas, las organizaciones con mayor número son Pro Esteros (16), la Red Calidad de Vida (16) y Haciendo lo Necesario (13), todas ellas pertenecientes al segundo subgrupo. Las osc con menor vinculación son Salvemos a la Diosa Tara (1), Ensenada No Aplaude la Crueldad Circense (1) y Desarrollo y Calidad de Vida (1), organizaciones pertenecientes al tercer subgrupo. Además, es el gobierno municipal con el que se relacionan mayormente las organizaciones, sin embargo, el gobierno federal tiene mejor calidad en las relaciones que establece con los grupos; por otra parte, en el gobierno estatal existe una menor intensidad y calidad en las gestiones. Además, el Centro de Investigación Científica y de Educación Superior de Ensenada (CICESE) y la UABC son las instituciones de investigación y educación (IIE) con las que más se vinculan las OSC; en el caso del CICESE lo hace principalmente con las organizaciones conservacionistas (primer subgrupo) y la UABC con los grupos de calidad de vida y sustentabilidad urbana (segundo subgrupo).

Sobre la posición de los actores en la red, la centralidad la ocupa Pro Esteros (1); en este sentido, se vincula con las organizaciones conservacionistas y con los grupos de sustentabilidad urbana, a la vez que mantiene relaciones con organizaciones internacionales, nacionales, instituciones de los tres niveles de gobierno y con instituciones académicas. Le sigue la Red Calidad de Vida (0.977), que se mantiene en el ámbito municipal, sin embargo, su relevancia estriba en que articula a las organizaciones locales con las instituciones académicas. En relación con la densidad de la red, el 
primer subgrupo es el más denso debido a que si bien su número de interacciones es menor que el segundo subgrupo, la calidad de sus relaciones es mayor. En el caso del tercer subgrupo, su densidad es menor debido a que sus interacciones son pocas y débiles (cuadro 1).

Cuadro 1. Principales características de los subgrupos de osc

\begin{tabular}{|c|c|c|}
\hline \multirow{5}{*}{ 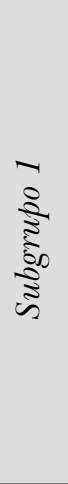 } & Agenda & Conservacionista. \\
\hline & Ámbito de gestión & Regional, a través de instituciones federales. \\
\hline & $\begin{array}{l}\text { Fuente de } \\
\text { financiamiento }\end{array}$ & Principalmente internacional. \\
\hline & Fortalezas & $\begin{array}{l}\text { Buen nivel de financiamiento, planeación de } \\
\text { sus actividades, alto grado de especialización del } \\
\text { personal y relación con instituciones académicas. }\end{array}$ \\
\hline & Principales retos & $\begin{array}{l}\text { Incrementar la legitimidad de su agenda en el } \\
\text { ámbito local y propiciar el desarrollo sustentable } \\
\text { de las comunidades. }\end{array}$ \\
\hline \multirow{5}{*}{ 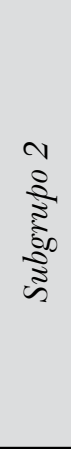 } & Agenda & Sustentabilidad. \\
\hline & Ámbito de gestión & Local, con instituciones municipales y estatales. \\
\hline & $\begin{array}{l}\text { Fuente de } \\
\text { financiamiento }\end{array}$ & Principalmente nacional. \\
\hline & Fortalezas & $\begin{array}{l}\text { Reconocimiento social y articulación a través de la } \\
\text { Red Calidad de Vida. }\end{array}$ \\
\hline & Principales retos & $\begin{array}{l}\text { Incrementar las fuentes de financiamiento, } \\
\text { mejorar la planeación y la especialización de sus } \\
\text { integrantes. }\end{array}$ \\
\hline \multirow{5}{*}{ 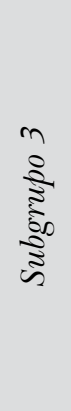 } & Agenda & Sustentabilidad. \\
\hline & Ámbito de gestión & Local, a través de gobierno municipal. \\
\hline & $\begin{array}{l}\text { Fuente de } \\
\text { financiamiento }\end{array}$ & Autofinanciamiento y en menor medida nacional. \\
\hline & Fortalezas & Temáticas novedosas que reciben apoyo social. \\
\hline & Principales retos & $\begin{array}{l}\text { Colaborar con instancias gubernamentales, } \\
\text { conseguir fuentes de financiamiento y } \\
\text { profesionalizar sus integrantes. }\end{array}$ \\
\hline
\end{tabular}

Fuente: Elaboración propia. 


\section{Discusión de resultados}

Como puede apreciarse, los vínculos interorganizacionales que se establecen son vastos e importantes, tanto en el plano municipal como en el estatal-nacional-internacional, eso proyecta el complejo entramado que se ha tejido en un lapso muy breve y evidencia los elementos que a continuación ponemos a discusión.

Primero, no existe un sólo tipo de osc ambiental en Ensenada y, en este sentido, se reconocen al menos tres subgrupos de organizaciones, que independientemente de su objetivo de trabajo, se asimilan entre sí y diferencian del resto de los grupos en función de sus relaciones con otros sectores. Estos subgrupos responden a dos agendas que en términos generales se construyen en diferentes niveles:

a) La agenda de conservación que baja de la esfera internacional y se inserta en el ámbito local. En este sentido, aunque existe un cambio en la concepción de la conservación a nivel mundial tendiente a integrar y proporcionar alternativas económicas a las comunidades, los proyectos de conservación llegan a ser conflictivos en el ámbito local, debido a que establecen restricciones en el uso de los recursos y costos específicos a sectores y actores, que pueden ser percibidos como injustos o descontextualizados (Abrams et al., 2003). Esta característica básica determina en gran medida que las osc en esta materia requieran de cuadros profesionalizados, un acceso continuo a recursos económicos y buen nivel en las relaciones con las instituciones gubernamentales encargadas de la conservación que se encuentran principalmente a nivel federal.

b) Las demandas dirigidas a mejorar la calidad de vida de la población, que constituyen una heterogeneidad de causas, fines, medios y actores, se construyen desde la base social, por lo cual, aglutinan recursos provenientes de la ciudadanía afectada o interesada. Esta premisa también determina la naturaleza de las organizaciones que no cuentan con una agenda compacta, tienen escaso financiamiento, el trabajo es de carácter voluntario, gestionan sus proyectos a nivel local y en gran medida existirán mientras sus objetivos y causas sean del interés de la población.

Segundo, el surgimiento tardío de las Osc ambientales en Baja California es resultado de dos momentos: el primero en la década de 1990, cuando emergen las organizaciones de conservación ligadas a la movilización 
de organizaciones estadunidenses originadas por el TLCAN (Torres, 1999, p. 476), que ha tenido repercusiones considerables en sus actividades como una cotidiana relación transnacional centrada en la mejora del flujo de recursos destinada a aumentar la capacidad productiva de las organizaciones mexicanas, y más importante, la influencia en la agenda ambiental de las OSC de Ensenada, que responde a tendencias muy marcadas por el lado norte de la frontera con Estados Unidos. El segundo momento es posterior a 2004, cuando se conforman las organizaciones que hemos clasificado como de sustentabilidad y calidad de vida, que concuerda con un interés en el ambiente más generalizado en la sociedad y con nuevos acercamientos sobre la concepción de la sustentabilidad que critican la incorporación del componente social como fin para alcanzar la sustentabilidad ecológica o el desarrollo económico, sin que los problemas sociales sean reconocidos por sí mismos como temas centrales (Foladori, 2002).

Tercero, los fondos disponibles para el trabajo de las osc son muy reducidos y, por ende, pueden desencadenar fenómenos como la competencia entre los grupos por obtener los financiamientos, la dependencia excesiva de alguna fuente, el condicionamiento en las actividades de las organizaciones debido a que son los proyectos de interés por parte de los fondos y la falta de ingresos constantes que pueden amenazar no sólo el desarrollo de actividades sino a las organizaciones mismas en el mediano y largo plazos. De esta manera, resalta la escasa participación gubernamental y de la iniciativa privada en el financiamiento de los grupos, que contrasta con la realidad de otras naciones en las que se realiza una labor más activa. También es relevante el papel de la sociedad en general, que está dispuesta a participar con trabajo voluntario pero no con aportaciones económicas; en este contexto, vale la pena cuestionar la capacidad de las OSC ambientales para desarrollar programas de procuración de fondos efectivos y el grado de corresponsabilidad que asumen las instancias gubernamentales, la iniciativa privada y la sociedad en general.

El cuarto es un proceso que permanece con el paso del tiempo, pues conforme se ha ido complejizando la red entre organizaciones, el contacto con los gobiernos permanece mínimo, más evidente a nivel municipal. Aunque los vínculos entre los dos actores parecieran fuertes, en gran medida son colaboraciones relacionadas con la superación de trabas burocráticas para su operación. Por ello, mejorar la calidad en la relación entre las OsC 
y el gobierno podría incrementar los beneficios de la gestión ambiental. Esto deriva en tres planteamientos: 1 . hasta qué punto las organizaciones conocen el trabajo gubernamental y sus mecanismos de consulta y participación; 2. cuando este conocimiento existe, cómo la falta de recursos disponibles por algunos grupos (dinero, tiempo, información, etc.) limita la consolidación de una relación de colaboración; y 3. de qué manera las instituciones gubernamentales gestionan la participación más allá de fines procedimentales, para incorporar las demandas de la sociedad civil y hacer atractivo para las osc la inversión de sus escasos recursos en los procesos participativos.

Quinto, las colaboraciones con las instituciones académicas aparecen también como mínimas, sin embargo, se reconoce que en estas instituciones se concentran importantes recursos informativos que pueden ser utilizados por las OSC para el alcance de sus objetivos. Esta característica puede deberse a fallos en la gestión de los grupos ambientalistas y a la visión disciplinaria de los grupos académicos, que se alejan de los problemas concretos y no generan información de fácil consumo por los actores sociales.

Sexto, aun con las debilidades y riesgos que presentan algunos grupos por sus características organizativas y el contexto en el que se desarrollan sus acciones. Un caso relevante es el de Pro Esteros, la organización local de mayor antigüedad, que funciona como interlocutora entre las osc, instituciones académicas, instancias gubernamentales y organizaciones nacionales e internacionales, y aunque su objetivo central es en materia de conservación, tejió una sólida alianza con las organizaciones de sustentabilidad que le permite ocupar un espacio central en la red. De esta manera, representa un referente frente al gobierno y la sociedad en general como una osc que ha logrado empoderarse, y entre las organizaciones de origen local, ejemplifica que es posible construir desde la sociedad civil un espacio de poder.

\section{Conclusiones}

Como se demuestra, las osc ambientales han crecido en un lapso muy corto, logrando posicionarse como un actor político de suma importancia con capacidad para condicionar no sólo la forma de gobernar (modificando políticas ya impulsadas) sino también los procesos políticos (insertando temas 
y actores en la agenda ambiental) y la acción conjunta de los grupos en red. De manera indirecta, tienen influencia regional/binacional mediante la colaboración en proyectos específicos con actores de diversas áreas geográficas. En resumen, las osc se constituyen como un capital sociopolítico clave en la gestión ambiental de la región, que deben ser fomentadas para mejorar la calidad de la gobernanza y la democracia.

El análisis de la encuesta nos permitió ver que la población que atienden es muy diversa y se centra en dos grandes agendas: la conservación y la sustentabilidad. Además, $60 \%$ de ellas toma decisiones mediante procesos de diálogo y consenso. El financiamiento proviene de dos fuentes principales: para las organizaciones que trabajan en materia de conservación, los recursos provienen de fondos internacionales, y en el caso de grupos que trabajan sustentabilidad, las aportaciones son realizadas por los socios y la población atendida. La red es extensa, y al menos 359 personas colaboran con las organizaciones, con un perfil de profesionales (53\% con licenciatura y $41 \%$ con posgrado) y casi la mitad son jóvenes menores de 29 años.

El estudio también mostró la aparición de tres grupos de osc. El primero más consolidado y vinculado a otros actores nacionales e internacionales, trabaja temas de conservación y se caracteriza por una mayor antigüedad. Otro grupo centrado en la sustentabilidad que opera en el nivel municipal y estatal, de menor antigüedad. Por último, uno que también opera en materia de sustentabilidad pero centrado en el ámbito local y de menos antigüedad.

En este caso, el escenario local es donde las osc desarrollan principalmente sus actividades, y representa un aspecto clave para los acuerdos surgidos del trabajo conjunto. El impacto de sus acciones puede mejorar al incrementar las interacciones entre los actores, ya que permitiría un mayor consenso, mayor acercamiento entre los actores y mejor conocimiento de los problemas. Sin embargo, las relaciones entre osc y los gobiernos aún son débiles, por lo que una tarea pendiente es analizar las barreras y brechas que frenan los procesos colaborativos entre ambos: 1 . sobre las características y debilidades que presentan las osc para integrarse en procesos participativos, y 2. en relación con las condiciones (o falta de ellas) que proporcionan las instituciones gubernamentales para incentivar la participación. 
Por otra parte, la interacción con otros actores (instituciones académicas, medios de comunicación, comercios y otras OSC a nivel nacional e internacional) permitiría reducir la dependencia de los recursos financieros para su operación (al disminuir los costos); asimismo, ayudaría a que se generara una agenda ambiental regional capaz de hacer contrapeso a las políticas que no respondan a las necesidades locales, a la colocación de temas urgentes en la agenda ambiental y, al mismo tiempo, a consolidar osc con una mayor planeación, presupuestación y visión a mediano y largo plazos.

Por consiguiente, las organizaciones dedicadas a la agenda de conservación y sustentabilidad atraviesan momentos dispares en sus procesos organizativos porque sus objetivos cuentan con apoyos provenientes de diferentes esferas. En el primer caso, los apoyos provienen del ámbito nacional/internacional, y en el segundo caso, del nivel local. Este contexto determina en gran medida sus características, estímulos, relaciones y potencial de incidencia. Por ello, las organizaciones que dirigen sus esfuerzos a mejorar la calidad de vida de la población y la sustentabilidad urbana tendrán escasez de recursos mientras se mantenga una perspectiva ecológica en la investigación académica del sector ambiental, el interés a nivel internacional se enfoque en la agenda de conservación y el papel del gobierno sea marginal en el estímulo de las actividades de las osc. Esto es relevante porque en estos grupos se articula un importante capital social y son el pulso de las demandas ambientales locales.

Desde la perspectiva de la teoría de la gobernanza y la participación ciudadana, las OSC ambientales deben mantener una presencia cada vez más constante en el escenario público puesto que aportan nuevas perspectivas y recursos en el manejo ambiental. En este proceso podrían beneficiarse: 1. los actores gubernamentales al utilizar los recursos y el capital social que aglutinan las osc, esto para mejorar el alcance de sus políticas y combatir la pérdida de legitimidad frente a la población; 2. la ciudadanía, al incrementar las vías de participación e incidencia política; y 3. la iniciativa privada, al aumentar su legitimidad en las comunidades locales y el reconocimiento de sus ideales, objetivos y formas de aprovechamiento de los recursos naturales. Sin embargo, en este caso la interacción entre los actores aún es débil porque los procesos de participación presentan barreras y los productos colaborativos son escasos. Debido a esto, existe 
un amplio margen para la colaboración entre actores que aún puede ser explorado para mejorar la gestión ambiental.

\section{Recomendaciones finales (marco de propuestas)}

En la medida de lo posible, se demostró que el contexto ecológico de Ensenada se configura como un espacio cruzado por múltiples intereses y acciones de distintos actores, cuya convergencia analizamos en las osc. El trabajo de éstas evidencia la necesidad de una gestión ambiental orientada a disminuir y/o aprovechar el conflicto social emanado por sus políticas, y ser posibilitadora de una mayor articulación tanto entre los grupos de osC que encontramos como entre los distintos actores que con ellas participan. Por ello, creemos que el trabajo pendiente debe partir desde dos aspectos, uno de corto plazo y otro de carácter más amplio y constante.

En el aspecto inmediato, se hace necesario que cada subgrupo de OSC aborde los retos que enfrentan para mejorar su influencia en el ámbito público. Por ejemplo, las organizaciones conservacionistas, al manejar una agenda que baja del ámbito internacional y tener una baja interacción con el ámbito local, deben mejorar la legitimidad de sus acciones entre la población local y empatar sus objetivos con el desarrollo sustentable de las comunidades. Las organizaciones con una agenda de sustentabilidad: 1. el grupo de mayor antigüedad debe fortalecer sus fuentes de financiamiento, mejorar sus procesos de planeación y buscar la profesionalización de sus integrantes; y 2. el de creación más reciente, debe aumentar su interacción con los actores gubernamentales para poder incidir en la política pública.

Nuestra propuesta de largo plazo se orienta hacia una reestructuración gubernamental multinivel (aplicada desde el nivel municipal, pero en la que se involucren los estados, la federación y las agencias binacionales) que incluya mecanismos de coordinación y negociación que privilegien a las OSC, su asociatividad y componente participativo, y asegure la inclusión de los individuos fuera de ellas, en la gestión conjunta de los problemas ecológicos, lo cual podría generar una reconfiguración del territorio, del ambiente y del uso de los recursos mediante propuestas ciudadanas y determinación conjunta de todos los actores sobre prioridades ecológicas en el municipio y sus diferentes zonas. 
Esta reestructuración se concretaría en la creación de un espacio deliberativo para todos los actores, llamados desde las osc, en la medida en que ya fungen como articuladoras de actores. Es cierto que ese tipo de instrumentos/herramientas ya existen (por ejemplo, la consulta ciudadana), pero no son permanentes, y al ser implantados desde el nivel más alto de la política gubernamental, es difícil que puedan ser asimilados. En este espacio todos los interesados en el uso de los recursos naturales pueden y deben plantear propuestas que, posteriormente, puedan ser llevadas directamente a la arena política y ser convertidas en políticas de gestión por actores gubernamentales.

En esta modalidad, se estimularían tanto el trabajo de las osc como el de los ciudadanos no comprendidos en ellas, proporcionando su incorporación al entramado gubernamental formal. Fortaleciendo, al mismo tiempo, el vínculo entre política y osc ambientales; es decir, acercando el aparato político, en particular los partidos políticos, a la compleja red aquí mostrada.

El espacio de negociación serviría también como espacio de encuentro, y gracias a la porosidad de las fronteras entre los actores, esto permitiría una reestructuración de la solidaridad (reconfiguración de la ciudadanía y el resurgimiento de la necesidad ciudadana de participar en la gestión ambiental), al tiempo que abriría oportunidades para la re-legitimación de múltiples ámbitos institucionales.

Dicha reestructuración no estaría orientada a evitar el conflicto por el uso de los recursos naturales ni a asegurar la legitimidad de la gestión ambiental actual (top-down), en tanto que el fin de la política consiste en negociar el disenso; al contrario, debe buscar la rearticulación y el desempeño público de las osc, los ciudadanos, las instituciones académicas, las fundaciones y demás aparatos políticos, permitiendo que las demandas y propuestas emanadas de este foro (bottom-up) sean negociables y procesables.

Este es el reto clave que buscamos atender con la anterior propuesta, una verdadera consolidación de las relaciones entre actores, pues aunque aparentemente conexos, sus vínculos son frágiles, haciendo necesaria la emergencia de una gestión ambiental más incluyente, más legítima y más fuerte.

Otro elemento importante sería realizar una investigación exhaustiva de los instrumentos y mecanismos previstos en la legislación ambiental 
para gestionar la participación, en función a las barreras y brechas que pueden generar para la participación social y la integración de las organizaciones ambientales. Con base en esta información, sería posible mejorar los mecanismos de participación existentes.

\section{Bibliografía}

Abrams, P., Borrini-Feyerabend, G., Gardner, J. y Heylings, P. (2003). Evaluating governance. A hanbook to accompany a participatory process for a protected area. Ottawa, Parks Canada: cmwg TILCEPA.

Acuña, C. y Vacchieri, A. (2007). La incidencia política de la sociedad civil. Argentina: Siglo Xxi Editores, Iniciativas.

Aguilar, L. F. (2010). Gobernanza: El nuevo proceso de gobernar. México: Fundación Friedrich Naumann para la Libertad.

Alfie C., M. (2001). Las redes de movimientos ambientalistas: ¿Solución frente al riesgo? El Cotidiano, 17(107), 89-100.

Alfie C., M. (2002). El medio ambiente en la frontera México-Estados Unidos: ¿Las ONG ambientalistas, nuevos actores sociales? Estudios Fronterizos, 3(5), 4375.

Ballester, A., Espluga, J. y Subirats, J. (2008). Participación pública en la Demarcación Hidrográfica del Ebro. Bilbao: Fundación Nueva Cultura del Agua.

Bassols, M. (2011). Gobernanza, una mirada desde el poder. En M. Bassols y C. Mendoza (Coords.), Gobernanza: Teoría y prácticas colectivas. Barcelona: Anthropos, Universidad Autónoma Metropolitana-Iztapalapa, División de Ciencias Sociales y Humanidades.

Bios. (2008). Manifestación de impacto ambiental. Ensenada, México: Hussong Marina International.

Bobadilla, M., Álvarez, S., Ávila, S., Lara, F. y Espejel, I. (2011). Evolution of environmental policy instruments implemented for the protection of totoaba and the vaquita porpoise in the Upper Gulf of California. Environmental Science \& Policy, 14(8), 998-1007.

Buendía, M. (2012). Humedales en riesgo por inmobiliarias. El Vigía. Recuperado de <http://www.elvigia.net/noticia/humedales-en-riesgo-por-inmobiliarias>.

Cabrero M., E. (2000). Usos y costumbres en la hechura de las políticas públicas en México: Límites de las Policy Sciences en contextos cultural y políticamente diferentes. Gestión y Política Pública, 9(2), 189-229.

Comisión para la Cooperación Ambiental. (2012). Acuerdo de Cooperación Ambiental de América del Norte, 2012. Recuperado de <http://www.cec.org/Page.asp?Pag $\mathrm{eID}=1226 \&$ ContentID $=\&$ SiteNodeID $=567>$. 
Comisión de Cooperación Ecológica Fronteriza. (2004). Acuerdo entre el gobierno de los Estados Unidos Mexicanos y el gobierno de los Estados Unidos de América sobre el establecimiento de la Comisión de Cooperación Ecológica Fronteriza y el Banco de Desarrollo de América del Norte: Autor.

Comisión Nacional de Áreas Naturales Protegidas. (2011). Áreas naturales protegidas federales de México. México: Autor.

Concepción, L. E. (2010). Gobernanza y democracia en América Latina en un contexto de globalización. En L. C. Montiel y P. M. Hernández(Eds.), Gobernanza global y democracia. Mexicali: Universidad Autónoma de Baja California.

Cheresky, I. (2005). Ciudadanía, sociedad civil y participación política. Argentina: Mino y Dávila Editores.

Day, D. (1997). Citizen participation in the planning process: An essentially contested concept. Journal of Planning Literature, 11(3), 421-434.

Delgadillo, J. (1998). Florística y ecología del norte de Baja California. Mexicali, Baja California: Universidad Autónoma de Baja California.

Di Paola, E., Sangalli, F. y Caorsi, S. (2011). Informe Ambiental Anual 2011. En P. d. M. A. Schiffrin (Ed.). Buenos Aires: Fundación Ambiente y Recursos Naturales.

Dukes, E. F. (1996). Resolving public conflict: Transforming community and governance. Manchester: Manchester University Press.

Durand S., L. F. D., Guzmán C., F. y Genet, M. (2011). La ecología política en México: ¿Dónde estamos y para dónde vamos? Estudios Sociales, 19(37), 282-307.

Red Europea de Lucha contra la Pobreza y la Exclusión Social. (2010). Guía metodológica de participación social de las personas en situación de pobreza y exclusión social. Madrid, España: Autor.

Enviromental Protection Agency. (1996). Border XXI Program. Washington: Autor. Espluga, J. y Subirats, J. (2008). Participación ciudadana en las políticas de agua en España. En L. H. M. del Moral (Ed.), Panel científico-técnico de seguimiento de la política de aguas. Sevilla: Universidad de Sevilla, Fundación Nueva Cultura del Agua.

Foladori, G. (2002). Avances y límites de la sustentabilidad social. Economía, Sociedad y Territorio, III (12), 621-637.

Font, J., Blanco, I., Gomà, R. y Jarque, M. (2000). Mecanismos de participación ciudadana en la toma de decisiones locales: Una visión panorámica. Documento presentado en el xiv Concurso de Ensayos del CLAD Administración Pública y Ciudadanía, Caracas, Venezuela.

Funtowicz, S. y Ravetz, J. (1993). Science for the post-normal age. Futures, 25(7), $735-755$.

Garretón, M.A. (2005). Sociedad civil y ciudadanía en la problemática latinoamericana actual. En C. Isidoro (Ed.), Ciudadanía, sociedad civil y participación política. Argentina: Miño y Dávila Edit. 
Graham, J., Amos, B. y Plumptre, T. (2003). Principles for good governance in the 21st Century. Ottawa: Institute on Governance.

Gutiérrez del Olmo, J. F. A. (1993). De la caridad a la asistencia. Un enfoque de la pobreza y la marginación en México. México: Secretaría de Salud.

Gutiérrez, P. M. y Garrido, F. J. (2006). Metodologías participativas de investigación y planificación del medio ambiente. En L. Camarero (Ed.), Medio ambiente y sociedad, elementos de explicación sociológica. Madrid: Thompson Editores.

Habermas, J. (1998). Facticidad y validez. Madrid: Trotta.

Instituto Municipal de Investigación y Planeación. (2007). Plan Municipal de Desarrollo 2008-2010. Ensenada, Baja California: Autor.

Instituto Municipal de Investigación y Planeación. (2010). Programa Parcial de Mejoramiento y Crecimiento Urbano del Sector Noreste. Ensenada, Baja California: Autor.

Instituto Nacional de Estadística y Geografía. (2010). Censo de Población y Vivienda 2010. Recuperado de < http://www.inegi.org.mx/sistemas/consulta_resultados/ iter2010.aspx?c $=27329 \& \mathrm{~s}=\mathrm{est}>$.

Irvin, R. A. y Stansbury, J. (2004). Citizen participation in decision making: Is it worth the effort? Public Administration Review, 64(1), 55-65.

Keohane, R. O. y Nye, J. S. (2000). Governance in a globalizing world. Nueva York: Brookings Press.

King, C. S., Feltey, K. M. y Susel, B. O. (1998). The question of participation: Toward authentic participation in public administration. Public Administration Review, 58(4), 317-326.

Kooiman, J. (2003). Governing as governance. Londres: Sage.

Leff, E. (2000). Pensar la complejidad ambiental. En E. Leff (Ed.), La complejidad ambiental. México: Siglo xxi.

Lezama, J. L. (2010). Sociedad, medio ambiente y política ambiental. En José Luis Lezama y Boris Graizbord (Eds.), Medio ambiente. México: El Colegio de México.

Lockwood, M. (2010). Good governance for terrestrial protected areas: A framework, principles and performance outcomes. Journal of Environmental Management, 91(3), 754-766.

Ludwig, D., Mangel, M. y Haddad, B. (2001). Ecology, conservation, and public policy. Annual Review of Ecology and Systematics, 32(32), 481-517.

Makoba, W. (2002). Nongovernmental organizations (NGOS) and third world development: An alternative approach to development. Journal of Third World Studies, 19(1), 53-64.

Meza, R. (2011). La Lagunita en peligro. zETA. Recuperado de < http://www. zetatijuana.com/2011/08/15/la-lagunita-en-peligro/ $>$.

Moreno Mena, J. A. (2008). Tejedores de esperanza. Redes de organizaciones civiles en Baja California. Mexicali, Baja California: Universidad Autónoma de Baja California. 
Morse, W. C., Nielsen-Pincus, M., Force, J. E. y Wulfhorst, J. D. (2007). Bridges and barriers to developing and conducting interdisciplinary graduatestudent team research. Ecology and Society, 12(2). Recuperado de <http:// www.ecologyandsociety.org/vol12/iss2/art8/>.

Myers, N., Mittermeier, R. A., Mittermeier, C. G., Da Fonseca, G. A. B. y Kent, J. (2000). Biodiversity hotspots for conservation priorities. Nature, 403(6772), 853-858.

Pavón, D. y Sabucedo, J. M. (2009). El concepto de sociedad civil: Breve historia de su elaboración teórica. Araucaria. Revista Iberoamericana de Filosofía, Política y Humanidades, 21, 63-92.

Peschard, J. (2006). Prólogo. En A. D. Selee y L. Santín del Río (Eds.), Democracia y ciudadanía: Participación ciudadana y deliberación pública en los gobiernos locales mexicanos. México: Woodrow Wilson International Center for Scholars-Ágora Ed.

Peters, G. B. y Pierre, J. (2005). ¿Por qué ahora el interés por la gobernanza? En A. C. I. Martínez (Ed.), La gobernanza hoy: 10 textos de referencia. Madrid: Instituto Nacional de Administración Pública.

Putnam, R. (1995). Bowling alone: America's declining social capital. Journal of Democracy, 6(1), 65-78.

Reyes R., M. (2006). Organizaciones no gubernamentales en Baja California: El caso de los grupos ambientales y de mujeres. Mexicali, Baja California: Universidad Autónoma de Baja California.

Ruiz, B. (2012). Continúa vigente Puerto Punta Colonet. Milenio. Recuperado de $<$ http://bajacalifornia.milenio.com/cdb/doc/noticias2011/36f56f290eedd5b2d $6 \mathrm{a} 8961 \mathrm{fb} 7662 \mathrm{ba} 0>$.

Sánchez, G. (2012). Sí a desaladora en La Lagunita. El Vigía. Recuperado de $<$ http://www.elvigia.net/noticia/s-desaladora-en-la-lagunita $>$.

Sandoval, F. (2012). El proyecto Punta Colonet recibe estocada final. Animal Político. Recuperado de <http://www.animalpolitico.com/2012/11/el-proyectopunta-colonet-recibe-estocada-final-de-la-sct/ $>$.

Santos, C. y Sánchez, V. (2007). Justicia ambiental: Participación pública en los procesos de toma de decisiones. En V. S. Munguía (Ed.), Gestión ambiental y de recursos naturales en México: Los modos imperantes. Tijuana, Baja California: El Colegio de la Frontera Norte.

Secretaría de Comunicaciones y Transportes. (2008). Proyecto multimodal Punta Colonet en Baja California. México: Autor.

Secretaría de Medio Ambiente y Recursos Naturales. (2008). Oficio No. DFBC/UGA/ DIRA/2894/08. Mexicali, Baja California: Autor.

Shannon, M. A. (2006). Participation as social inquiry and social learning. Schweizerische Zeitschrift fuer Forstwesen, 10(150), 430-437.

Shevock, J. y Taylor, D. W. (1987). Plant exploration in California the frontier is still here. En T. S. Eias y J. R. Nelson (Eds.), Conservation and management 
of rare and endangered plants. Sacramento, California: California Native Plant Society.

Torres, B. (1999). Las ONG ambientalistas en las relaciones México-Estados Unidos. Foro Internacional, 39(4), 453-478.

Turnhout, E., Bommel, V. S. y Aarts, N. (2010). How participation creates citizens: Participatory governance as performative practice. Ecology and Society, 15(4), 26. Recuperado de < http://www.ecologyandsociety.org/vol15/iss4/art26/>. Vallespín, F. (1996). Sociedad civil y crisis de la política. Isegoría, 22(13), 39-58.

Velázquez G., M. A. (2007). Pespectivas del movimiento ambiental en la frontera entre México y Estados Unidos: Acciones y necesidades. Región y Sociedad, XIX, (Número especial), 171-197.

Venegas, R. (2007). Aptitud territorial: Una aproximación hacia la planeación y el ordenamiento del territorio. Mexicali, Baja California: Universidad Autónoma de Baja California.

Anexo 1. Listado de organizaciones ambientales en Ensenada

\begin{tabular}{|l|c|l|}
\hline \multicolumn{1}{|c|}{ Nombre } & Conformación & \multicolumn{1}{|c|}{ Objetivo general } \\
\hline Pro-Esteros, A.C. & 1988 & Conservación principalmente de humedales. \\
\hline $\begin{array}{l}\text { Pronatura Noroeste, } \\
\text { A.C. }\end{array}$ & 1991 & $\begin{array}{l}\text { Conservación de ecosistemas mediterráneos } \\
\text { y costeros. }\end{array}$ \\
\hline $\begin{array}{l}\text { Grupo de Ecología y } \\
\text { Conservación de Islas, } \\
\text { A.C. (GECI). }\end{array}$ & 1998 & Conservación de islas. \\
\hline $\begin{array}{l}\text { Comité Ecológico } \\
\text { Chapultepec. }\end{array}$ & 2001 & $\begin{array}{l}\text { Apropiación del parque "Arroyo el } \\
\text { Campillo". }\end{array}$ \\
\hline Terra Peninsular, A.C. & 2003 & $\begin{array}{l}\text { Limpieza y apropiación de playas en } \\
\text { Ensenada. }\end{array}$ \\
\hline $\begin{array}{l}\text { Grupo Pro-Playitas, } \\
\text { A.C. }\end{array}$ & 2004 & $\begin{array}{l}\text { La conservación y protección de la } \\
\text { biodiversidad a través del derecho. }\end{array}$ \\
\hline $\begin{array}{l}\text { Defensa Ambiental del } \\
\text { Noroeste, A.C. }\end{array}$ & 2007 & $\begin{array}{l}\text { Apropiación de playas en la localidad, en } \\
\text { especial la Lagunita del Ciprés, y educación } \\
\text { ambiental. }\end{array}$ \\
\hline $\begin{array}{l}\text { Haciendo lo Necesario, } \\
\text { A.C. }\end{array}$ & $\begin{array}{l}\text { Conservación de la zona costera, } \\
\text { recuperación de la cuenca del río Tijuana y } \\
\text { río Otay, y proyectos de protección de vida } \\
\text { silvestre. }\end{array}$ \\
\hline \begin{tabular}{l} 
Costasalvaje, A.C. \\
\hline
\end{tabular} & 2007 \\
\hline
\end{tabular}




\begin{tabular}{|c|c|c|}
\hline Jamaak Escuela Verde. & 2008 & $\begin{array}{l}\text { Promoción de cultivos urbanos a través de } \\
\text { técnicas como la hidroponía, compostaje y } \\
\text { permacultura. }\end{array}$ \\
\hline Surf-Ens, A.C. & 2008 & $\begin{array}{l}\text { Protección y conservación de playas para la } \\
\text { práctica de surf. }\end{array}$ \\
\hline $\begin{array}{l}\text { Asociación Protectora } \\
\text { de Animales } 4 \text { Patas, } \\
\text { A.C. (4 Patas). }\end{array}$ & 2008 & $\begin{array}{l}\text { Protección de mascotas a través de } \\
\text { esterilización y adopción de animales en } \\
\text { condición de calle. }\end{array}$ \\
\hline $\begin{array}{l}\text { Desarrollo y Calidad de } \\
\text { Vida, A.C. }\end{array}$ & 2008 & Promoción del desarrollo sustentable. \\
\hline $\begin{array}{l}\text { Grupo Pro Ciclo Va, } \\
\text { A.C. }\end{array}$ & 2009 & $\begin{array}{l}\text { Promoción de la cultura ciclista en la ciudad } \\
\text { y una red de ciclovías. }\end{array}$ \\
\hline UABici. & 2010 & $\begin{array}{l}\text { Promoción de la cultura ciclista entre la } \\
\text { comunidad universitaria. }\end{array}$ \\
\hline $\begin{array}{l}\text { Salvemos a la Diosa } \\
\text { Tara. }\end{array}$ & 2010 & $\begin{array}{l}\text { Apropiación y recuperación del parque del } \\
\text { cerro "El Keki". }\end{array}$ \\
\hline $\begin{array}{l}\text { Ensenada No Aplaude } \\
\text { la Crueldad Circense. }\end{array}$ & 2010 & Erradicar la crueldad hacia los animales. \\
\hline Skate Baja, A.C. & 2010 & $\begin{array}{l}\text { La apropiación y recuperación de parques } \\
\text { para la práctica de patinaje. }\end{array}$ \\
\hline $\begin{array}{l}\text { Estudios y Propuestas } \\
\text { para la Conservación, } \\
\text { A.C. }\end{array}$ & 2010 & Conservación de tierras privadas. \\
\hline $\begin{array}{l}\text { Transición Ensenada, } \\
\text { A.C. }\end{array}$ & 2010 & Promueve un estilo de vida más sustentable. \\
\hline Enseduca, A.C. & 2011 & $\begin{array}{l}\text { Promueve la educación ambiental } \\
\text { principalmente en colonias en condiciones } \\
\text { de marginación dentro de la zona urbana. }\end{array}$ \\
\hline $\begin{array}{l}\text { Tierra Colectiva: } \\
\text { Ciudadanía, Género y } \\
\text { Medio Ambiente, A.C. }\end{array}$ & 2011 & $\begin{array}{l}\text { Construir eco-ciudadanía y propiciar un } \\
\text { contexto de gobernanza ambiental. }\end{array}$ \\
\hline
\end{tabular}

